\title{
Dynamics Of US Economic Recovery: Can We Still Count On The Finance And Insurance Sector?
}

Rexford Abaidoo PhD, University of Maryland Eastern Shore, USA

\begin{abstract}
This study takes a quantitative approach to examine the dynamic effects of post-recession sector and sub-sector growth performance of U.S. economic recovery. The study employs contributions to GDP growth rate among selected sectors and sub-sectors of the US economy to measure the probability to significantly impact the rate of economic recovery. Estimation results based on logistic model indicates the finance and insurance sector of the economy is still critical to US economic recovery after a major macroeconomic shock; however, the sector's potential to significantly accelerate economic recovery seem to be overstated compared to other key sectors of the economy. Further test suggests the real estate sector of the economy is significantly weak in generating growth levels required to significantly accelerate economic recovery after major economic shock such as the recession of 2008.
\end{abstract}

Keywords: US Economic Recovery; Odds Ratio; Economic Sector Performance; Finance and Insurance Sector

\section{INTRODUCTION}

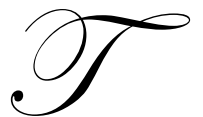

he relative ease with which firms and establishments in the finance, insurance and real estate sectors succumbed to the economic shock of 2008, brought into question the presumed resilience of firms in these key sectors to macroeconomic shocks. The ongoing weak recovery trend continues to heighten concerns about the ability of key sectors of the US economy to propel the economy back onto a steady and sustained growth trajectory after a major shock. According to the Congressional Research Service, ongoing economic recovery process started in mid 2009 after the initial collapse brought about by the 2008 recession. Most analysts at the time (beginning of the third quarter of 2009) expected and projected some semblance of full recovery by the first quarter of 2011. However, the recovery process, as evidenced by key economic indicators, has been painfully slow compared to similar rebound conditions characterizing other developed economies around the world. The German and the Canadian economies have for instance made relatively faster progress towards full economic recovery than the US economy. Major macroeconomic indicators still show the US economy is not fully on an upward swing mode toward full recovery anytime soon. Job growth numbers have fluctuated widely since the latter part of 2009. Moderate growth occurring among firms in some sectors of the economy continues to be interrupted by slowdown in other key sectors of the economy. Fluctuations in unemployment numbers and productivity levels, wavering consumer confidence indicators, etc continue to be a feature characterizing the ongoing recovery. With the manufacturing sub-sector of the US economy still reeling from massive outsourcing and ever-expanding potential of the Chinese manufacturing sector, the finance, insurance and real estate sub-sectors were perceived by some analysts as areas where the United States could still maintain its competitive edge. However, with the onset of the 2008 recession and the decimation of the finance and insurance sector which followed, most economists are now skeptical about the finance and insurance sectors' ability to sustain the economy's competitive edge through accelerated recovery toward pre-2007-2008 recession growth trajectory.

Most leading indicators currently point to appreciable but fluctuating growth conditions among key sectors of the US economy. No particular sector, however, has emerged as the dominant sector with sustained growth trend to lead the way toward the long awaited full economic recovery. Quarterly sector growth data from Bureau of 
Economic Analysis documents continued significant growth trend among various sectors and sub-sectors of the economy. This trend has however been gravely unreliable, making it very difficult to point to a single sector of the economy as the engine driving the ongoing recovery process. Sector specific contribution to GDP growth indicators from early part of 2010 for instance, show that growth trend among key economic sectors lag behind levels needed to ensure acceleration towards full economic recovery. Despite these challenges in the recovery process across sectors of the US economy, growth trend among firms in the finance and insurance sectors seems to have emerged as the leading barometer by which most analysts and the average American measures the pace of the ongoing economic recovery. This study estimates this potential to significantly impact economic recovery by key sectors and sub-sector of the US economy after a major shock with the finance and insurance sectors as the focus.

According to the Bureau of Economic Analysis (BEA), weakening economic activity in the finance and insurance industry accounted for about half of the stagnation in economic activity in 2007 prior to the economic collapse. Systemic stagnation in activities within the industry, according to the Bureau's briefings, generated conditions which precipitated and ultimately culminated in the 2008 recession. Available data on the industry's contributions to real gross domestic product (GDP) growth from the Bureau (BEA) show that decline in growth among firms in the finance and insurance sector contributed significantly to the 2008 recession. For instance, BEA data show that the finance and insurance sectors' value-added over the period - a measure of the sectors' contribution to GDP fell 0.3 percent in 2007 after rising 9.8 percent in 2006. The data also documents that other sectors of the economy did not fair better during the same period. For instance, the construction industry's valueadded (contribution to GDP) declined 12.1 percent in 2007 prior to the economic downturn, after falling 6.0 percent in 2006. Additionally, the real estate, rental and leasing sector's contribution to GDP also slowed to 2.1 percent in 2007 from 3.4 percent growth in 2006. In the mining sector, value addition to GDP grew less than 0.1 percent in 2007 after recording 6.1 percent growth in 2006. These growth dynamics highlights conditions which persisted prior to the onset of what became one of the worse economic conditions witnessed in US economic history. These trends further lends credence to the view that the economic collapse of 2008 was set in motion in part by major decline in growth among firms in key sectors of the US economy.

In order to understand post recession US sectors and sub-sectors' growth dynamics and how such growth impact rate of economic recovery, this study is structured to measure critical role of the finance, insurance and real estate sectors of the US economy in accelerating economic recovery after a major shock such as the 2008 downturn. The focus on these sub-sectors of the economy has been necessitated by growing skepticism on the sector's ability to spearhead accelerated recovery of the US economy after a major shock. Critics argue that having been the core segment of the US economy which precipitated and ushered in one of the worse recessions in the nation's history, the same segments cannot be relied upon to achieve full economic recovery and put the US economy back on sustained growth trajectory. Globalization and rapid expansion of financial markets around the world, according to some critics, continue to diminish the finance and insurance sectors' historical potential and strength in the economic growth and recovery process. To these critics, there is the need to consider other sectors of the US economy as potential engines of growth and drivers of recovery to help sustain the US economy's competitiveness amid growing competition from the Chinese and other emerging economies around the world.

Although ascertaining the recovery augmenting potential of post economic shock finance, insurance and real estate sector of the US economy is the prime goal of this study, tests conducted are not limited to these subsectors. In order to provide comparative assessment among key sectors of the US economy, this study also estimates recovery augmenting potential of other core sectors and sub-sectors of the economy to assess how they generate and provide the impetus critical in accelerating US recovery process. This approach is meant to test the view that other sectors of the economy might be more critical to US economic recovery than the finance, insurance and real estate sub-sectors of the economy. The rest of the study is structured as follows: The next section reviews the literature on the relationship between activities and operations in the finance and insurance sector and economic growth and recovery; followed by a section addressing some of the factors put forth as being responsible for the slower than expected recovery pace of the US economy. Section four introduce and develops statistical framework for capturing the probability of impacting economic recovery features associated with selected sectors and sub-sectors of the US economy; the section also test and presents empirical results of the study. Discussion of results and policy implications are analyzed in the final section. 


\section{THE LITERATURE}

\section{Financial Sector Development, Operations and Economic Growth}

Available literature presents legion of empirical studies which address the nature of the relationship between activities and operations in the finance and insurance sector and variability in economic growth and development. Documented findings presented in these studies have provided critical insight on the underlying processes within the financial and insurance sector which ultimately augments the growth process in a steady economy. The literature, to some degree, also provides information on the unique role of the finance and insurance sector in economic recovery after a major shock; that is, by rechanneling investment funds and resources to productive sectors of the economy. In an assessment of the root cause of the 2008 economic shock and how the ongoing recovery process could be accelerated, Brown and Lundblad (2009) showed that although the 2008 recession was initiated by the mortgage crisis in the financial sector, positive developments within the sector could still provide the economic jolt needed to accelerate full recovery of the US economy. After careful analysis of the core factors which accounted for the 2008 recession, Brown and Lundblad (2009) found that full recovery of the US economy could only be achieved through a thaw and rebound in the credit market. Thus, notwithstanding its role in the economic collapse, the finance and the insurance sector of the economy is still essential in economic recovery. The economic slowdown of 2008 had the effect of freezing out the flow of investment funds critical in sustaining growth and keeping the US economy on stable and competitive trend. Brown and Lundblad (2009) further provided evidence in support of the well entrenched view that the US financial system is the lifeblood of the economy, and its smooth functioning is necessary for any eventual rebound. This conclusion to some degree highlights the importance most researchers attach to the role played by the finance and insurance sector in economic recovery.

Greenwood and Jovanovic (1990) modeled the dynamic interactions between financial sector activities and economic growth, and found that financial intermediation and its auxiliary operations in a financial system produce critical information crucial in investment decisions. The study showed that services and information provided by various intermediaries in the financial sector directly impacts the magnitude and spread of investments which spurs and impact the rate of economic growth. Given the established positive correlation between rate of investment growth and economic growth (Output(Y) or GDP function), the study in order words, suggest that financial intermediation activities (a core operation in the financial sector) is crucial for accelerated economic recovery. Additionally, operations in the financial sector have also been found to significantly impact economic growth and recovery by serving as conduits for resource allocation to various productive sectors of the US economy. Idle funds invested in the financial sector are ultimately channeled into ventures with potential to spur economic growth. Thus, there are significant interactions between financial sector operations and economic growth and recovery. Rousseau and Wachtel (1998) tested this interaction between financial sector development and growth for five economies and showed that there exists significant causal relationship between financial sector development and economic growth; with direction of causality running from financial sector development to economic growth. Arestis et al (2001) further found evidence in support of Rousseau and Wachtel's (1998) study. Arestis et al additionally showed that growth in financial sector activities stimulate and granger cause economic growth and recovery.

In a re-examination of the finance-growth nexus, Rousseau and Wachtel (2005) found that although the positive relationship associated with the finance-growth nexus is firmly established in evolving empirical literature, studies questioning the strength of this empirical link have also grown in recent years. To re-examine this link, Rousseau and Wachtel retested the strength of the financial sector development-economic growth relationship using relatively recent data set. Results showed that the finance-growth relationship is not as strong as has been found in earlier studies. The study found diminishing strength in the finance-growth nexus when more recent data sets are employed. This conclusion to some degree reflects growing view among critics about the weakening role of the US financial sector in economic growth and recovery.

Christopoulos and Tsionas (2004) employed cointegration procedures to examine the relationship between financial sector development and economic growth in ten developing economies. The study found strong evidence of long run casual relationship running from financial sector development to economic growth. Demirguc-Kunt and Levine (2001) further documents that economies tend to receive greater returns to growth when they focus on total financial sector development; a condition which further lend support to positive correlation between financial sector 
operations and economic growth. Beck and Levine (2002) also confirmed that greater financial sector development accelerates growth of financially dependent industries. Given that more than $70 \%$ of firms in various sectors of the US economy tend to fall into this category; this study further points to the critical role of the finance sub-sector in economic rejuvenation and growth. In a comprehensive study to survey and test the finance-growth nexus, Manning (2003) based his study on the work of Rajan and Zingales (1998a) and Levine and Zervos (1998). Manning (2003) documents that finance (a component of financial sector operations) has significant impact on growth and recovery; and this growth is more pronounce among non-OECD (Organization for Economic Co-operation and Development) economies; with bank finance being the dominant operational feature.

Levine, Ross (2004) conducted extensive review of the various theoretical and empirical studies focusing on the relationship between financial system operations and economic growth. The study found overwhelming empirical evidence in support of the positive association between financial sector development, financial intermediation and markets and economic recovery and growth. The study also noted that empirical results presented in existing literature are in synch with the view that 'better developed financial system loosens external financing constraints facing firms; a condition which illuminates a key mechanism through which financial development influences economic growth'. De la Fuente and Martin (1995) further points out that financial system actors and general operations within a financial sector tend to improve overall credit allocation which positively impact economic growth. In an analysis of how fiscal stimulus and financial rehabilitation impact economic recovery, Zhang and Zhang (2010) also document that both fiscal stimulus and financial sector rehabilitation contribute significantly to economic recovery and are key in accelerating growth after a major economic shock. The study also found that between the two, the impact of financial sector rehabilitation on economic recovery tend to be more pronounce in developed economies like the United States. There is thus, sufficient theoretical and empirical evidence in support of long term causal relationship between financial sector development, operations in a financial system and economic recovery and growth.

\section{Insurance Industry Operations, Economic Recovery and Growth}

The insurance industry constitutes one of the key components in the economic recovery and growth process. Although operations and activities within the industry are often considered second tier to other major institutions and sectors of the US economy, efficient operation of the industry is crucial in easing ongoing constraints on US economic recovery. A key role played by the insurance industry in economic recovery (growth) is its pivotal role as the core sector around which commerce and business transactions revolve. The insurance industry promotes and sustains investment confidence; a condition critical for sustained economic activities and growth. The ability to transfer, negate or minimize risk provided by the insurance industry makes engagement in economic activities more appealing to businesses, firms and potential investors. Supporters of this view (on the core role and service provided by the insurance industry) argue that without this ability to transfer risk and negate potential losses, the US economy would virtually grind to a halt. Growing uncertainties and potential for losses will diminish propensity to invest, make investors more hesitant and ultimately constrain investment and economic growth. If recent investments growth trend after the 2008 recession is anything to go by, then it could be argued that most investors and firms will be hesitant to make substantial investment without adequate cushion against risk and uncertainties. The insurance industry in this sense provides the avenue to ease these concerns; this service by the industry creates the environment needed to promote growth in investments and acceleration in economic recovery and growth. Inefficient or struggling insurance industry will however, tend to constrain investments in productive but risky ventures with the potential to spur growth. The insurance industry in this sense acts as the principal agent in securing business transactions and improving investment confidence which in turn generates and sustains growth throughout the economy.

The insurance industry also makes immense contribution to the multiplier effects process responsible for economic growth and recovery. Property-casualty insurers alone are estimated to employ over 600,000 individuals and households, which translate into over $\$ 34$ billion in wages and salaries. Channeling these wages and salaries into consumption and investment through savings further augments and generates expansion in productivity which ultimately enhances economic growth. At the state level, the insurance industry also contributes significantly to states budget which provide the needed resources for development and growth. The insurance industry pays millions of dollars in state premium taxes, accounting for a very significant portion of state-level developmental revenue 
crucial for economic growth. Additionally, the insurance industry also creates huge pools of capital in its operations which when made available to the financial markets help promote and sustain investment and economic growth.

Marco Arena (2006) tested causal relationship between insurance market activity and economic growth. The study employed panel data for 56 countries spanning the period 1976-2004. The study found robust causal relationship between insurance market activities and economic growth. Property and other nonlife insurance operations were found to have positive and significant causal effect on economic growth. İlhan EGE et al (2011) further provides evidence in support of the positive relationship between insurance sector activities and economic growth. In a related study, Ćurak, Lončar and Poposki (2009) examined relationship between insurance sector development and economic growth in 10 transition European Union member countries. Fixed-effects panel model which controlled for other relevant determinants of economic growth and endogeneity supported prevailing conclusion that insurance sector development positively and significantly affects economic growth.

\section{Finance and Insurance Sector Operations and Economic Recovery}

The Finance and Insurance services sector is fundamental to US economic recovery and continual growth. Institutions and firms found in the sector have over the years provided the platform and channels, as well as the core building blocks around which US economic growth potential revolve. The critical role played by the finance and insurance sector as documented by empirical studies such as (Levine, Ross (2004), Arestis, Demetriades and Luintel (2001) is not only limited to the ultimate growth of the US economy. Operational activities within the sector have also been found to be cogent in economic recovery after a major shock or severe economic slowdown. Available data indicates US economic sectors in general continue to experience appreciable rebound after the 2008 economic shock. This trend has however, not been a sustain one to ensure acceleration in recovery as already noted. Most economic indicators continue to show extreme growth volatility among key sectors of the economy. Despite the continued vacillations in growth trend among various sectors of the economy, the finance and insurance sector is still perceived by some as the sector with the needed potential to fuel the recovery process. Some analysts argue that, despite a near collapse in 2008 , the finance sector continue to channel resources towards various productive sectors of the economy and provide the needed investment funds and opportunities critical to the recovery process. The sector also continues to create the environment for growth in investments despite lingering uncertainty about the strength of the recovery process. This study examine this role by the finance and insurance sector in post-economic shock recovery by estimating the potential to substantially impact economic recovery after a major shock to the US economy.

\section{FACTORS ACCOUNTING FOR SLOWER THAN EXPECTED FULL US ECONOMIC RECOVERY}

A number of factors have been identified as being responsible for the slow pace of recovery after the 2008 economic shock. This section reviews some of the leading factors. Prominent among these factors is the scope and severity of the 2008 economic shock. Proponents of this view suggest the slow recovery process could be attributed to the magnitude and the severity of the 2008 recession. Compared to other periods of economic downturn in recent US economic history, the 2008 economic shock according to proponents was more pervasive, and impacted wider segment of the core sectors of the US economy than recessions of recent years. Supporters of this view argue that heavy losses recorded in the financial sector alone due to the mortgage crisis dealt devastating blow to consumer confidence leading to stagnation in consumption and productivity, which ultimately led to decline in investment. Although the 2008 recession was set in motion by the housing market collapse, the impact according some analysts went far beyond the real estate sub-sector of the economy. The 2008 economic slowdown severely uttered expectations on investments prospect leading to major decline in propensity to invest and a decline in economic growth. According to the Congressional Research Service, real gross domestic product fell by almost $4.0 \%$ over the period; which translates into about $\$ 500$ billion loss in economic transaction over the period. This decline in general economic activity over the period supports the view that the 2008 recession was more severe compared to the two most recent recessions in 2001 and 1990 respectively.

Another condition sited as a contributing factor to the weak US economic recovery deals with what has been referred to as the 'hangover' from the 2008 economic shock. Supporters of this view contend that banks and other financial institutions impacted during the economic slowdown are now more hesitant to lend to businesses and 
firms with viable investment opportunities. This constrain on investment funds availability according to some analysts constitutes one of the key factors accounting for the slow pace of the ongoing recovery. Additionally, restructuring and changes in modus operendi by most banks and financial institutions in the wake of the economic shock have made it extremely difficult for small scale firms and new ventures as well as corporations to secure the needed funds for expansion and new investments - a condition which continue to frustrate the very process responsible for growth and accelerated recovery. Ventures and projects with good prospects which were readily financed prior to the economic shock are now being rejected due to new stringent policies introduced in the wake of the economic meltdown. This 'hangover' from the economic slowdown according to proponents, continues to stifled innovation and investments crucial in bringing about desired growth and economic recovery. According to the Bureau of Economic Analysis, investment spending alone constitutes the third largest component of aggregate spending; averaging $17 \%$ to $18 \%$ of GDP in years of near normal output growth. Given this significant contribution to GDP, it is evident that any significant decline in investment growth due to 'hangover' from economic slowdown will have adverse effect on the rate of recovery of the US economy.

Additionally, adjustments and acclimatization to post economic slowdown conditions by corporations and firms have, also been being identified as key factors accounting for the weak recovery process. Supporters of this view contend that the 2008 economic shock brought in its trail the need for firms and corporations to adapt to the 'new business environment' in order to survive. Having made critical adjustments, which for most firms entailed decreasing productivity and downsizing, most firms are now either unwilling or find it difficult to quickly reverse operational adjustments they have become accustomed to for well over a year. For most firms in the various sectors, adjustment made after the economic slowdown has become the norm, which they find no economic reason to reverse given prevailing climate of uncertainty characterizing current recovery trend. Lingering uncertainties prevailing in the financial market, coupled with volatile oil prices and weak consumer sentiments makes most firms and corporations very hesitant to restore operations to pre-recession production levels - a condition which continues to weaken the pace of economic recovery.

Another key factor accounting for the slower pace of US economic recovery relates to fiscal policy initiatives implemented by the federal government in the wake of the mortgage crisis. Analyst point out that economic boost from last year's fiscal package implemented by the federal government in the wake of the crisis had the effect of temporarily cushioning the economy from the brink of total collapse. The sustaining effect of this policy by the federal government has however, begun to wane. This waning effect has, to some extent impacted the pace of the ongoing recovery process; making the economy more susceptible to both external and internal shocks, such as oil price fluctuations and currency manipulation among some Asian economies. The slow pace of the ongoing recovery has also been attributed to the failure of the Federal Reserve's low interest rate policy to attract expected investments and revive consumer confidence. Analysts suggest that lagging investment growth despite record low interest rate policy has also contributed significantly to the slow pace of US economic recovery.

\section{TEST VARIABLES AND DATA}

Rate of the US economy recovery in this study is coded as dichotomous dependent variable of either experiencing accelerated economic recovery prospect (1) or otherwise (0). This variable is computed using rate of change in US unemployment rate. The choice of rate of change in US unemployment rate as a measure of rate of economic recovery, is based on the assumption that the change (change in US unemployment rate) tend to explain more of the variability in the rate of economic recovery all things being equal. Additionally, the rate of change in unemployment rate also tends to serve as a good indicator of US economic recovery. Explanatory variables tested in this study include contributions to GDP growth by selected key sectors and sub-sectors of the US economy with particular emphasis on the finance and insurance sector of the economy. Sectors tested in this study include: the mining sector, utility industry, finance and insurance sector, construction, manufacturing, wholesale, retail, transportation and warehousing, information, real estate, professional and business services, government and professional, scientific and technical services sectors of the economy as disaggregated by the Bureau of Economic Analysis. 


\section{EMPIRICAL FRAMEWORK}

\section{Model Specification: The Logistic Model}

General logistic model is specified as follows:

$$
\begin{aligned}
& \operatorname{Pr}\left[Y_{j}=1 \mid X_{1 j}, \ldots X_{k j}\right]=F\left(\beta_{1}^{0} X_{1 j}+\ldots \ldots \beta_{k}^{0} X_{k j}\right) \\
& F(x)=\frac{1}{1+\exp \left(-\beta_{1}^{0} X_{1 j}-\cdots-\beta_{k}^{0} X_{k j}\right)}
\end{aligned}
$$

where:

$X i j$ 's in equation 1 represent the explanatory variables, $\beta_{1}^{0}$ 's are the unknown coefficient parameters to be estimated and equation 2 is the distribution function or the logistic (logit) distribution function. This model can be estimated by means of Maximum Likelihood in log-likelihood function as follows:

$$
\operatorname{In}\left(L_{n}\left(\beta_{1, \ldots . .}, \beta_{k}\right)\right)=-\sum_{j=1}^{n}\left(1-Y_{J}\right) \sum_{i=1}^{k} \beta_{i} X_{i j}-\sum_{j=1}^{n} \ln \left(1+\exp \left(-\sum_{i=1}^{k} \beta_{i} X_{i j}\right)\right)
$$

Based on equation 1, the full model testing for the probability threshold of how growth dynamics among selected sectors of US economy influence acceleration in economic recovery is expressed as follows:

$\operatorname{Pr}\left[Y_{j}=1 \mid X_{1 j}, \ldots X_{k j}\right]=F\left(\begin{array}{c}\beta_{1}^{0} \text { Profbu }_{1 j}+\beta_{2}^{0} \text { Infor }_{2 j}+\beta_{3}^{0} \text { Min }_{3 j} \\ +\beta_{4}^{0} \text { RealE }_{4 j}+\beta_{5}^{0} \text { Manu }_{5 j}+\beta_{6}^{0} \text { Whol }_{6 j} \\ +\beta_{7}^{0} \text { Gov't }_{7 j}+\beta_{8}^{0} \text { Const }_{8 j} \ldots . . \beta_{k}^{0} X_{k j}\end{array}\right)$

Where: $\operatorname{Profbu}_{1 j}$, Infor $_{2 j}, \operatorname{Min}_{3 j}$ etc are professional business sector, the information sector, the mining sector, real estate sector, the manufacturing sector, wholesale sector, government sector, construction sector and other selected sectors and sub-sectors of the US economy as categorized by the US Bureau of Economic Analysis and Bureau of Labor Statistics.

Equation 4 is tested using robust logistic regression analysis. Logistic output provided by most statistical software packages mainly reports odds ratios. The odds ratios are subsequently converted into probabilities in this study in order to measure the likelihood of accelerating economic recovery potentials characterizing selected sectors and subsectors of the US economy after a major economic shock.

Let Odds Ratios of selected individual sectors and sub-sectors of the US economy presented in equation 4 be modeled as follows:

$$
\frac{P}{1-P}=e^{a+\beta_{1}^{0} \text { profbu }_{1 j}+\beta_{2}^{0} \text { infor }_{2 j}+\beta_{3}^{0} \min _{3 j}+\cdots \ldots . . \beta_{k}^{0} X_{k j}}
$$

Where $e^{a+\beta_{1}^{0} \text { profbu }_{1 j}+\beta_{2}^{0} \text { infor }_{2 j}+\beta_{3}^{0} \min _{3 j}+\cdots \ldots . . \beta_{k}^{0} X_{k j}}$ is the exponent of constant and beta coefficients of various independent variables in equation 4 (odds ratios).

Based on equation 5, the probability that growth features associated with sectors or sub-sectors of the US economy provides the impetus critical for acceleration in economic recovery could be stated as follows:

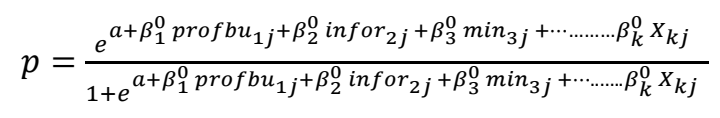


Where $P$ estimates the probability of impacting the rate of economic recovery by a sector of US economy

\section{EMPIRICAL RESULTS}

Table 1 presents logistic odds ratios and the probability of augmenting economic recovery parameters associated with selected sectors and sub-sectors of the US economy. Sectors are grouped into three segments to minimized interaction effects.

Logistic Table 1: The Probability of Augmenting Accelerated Economic Recovery

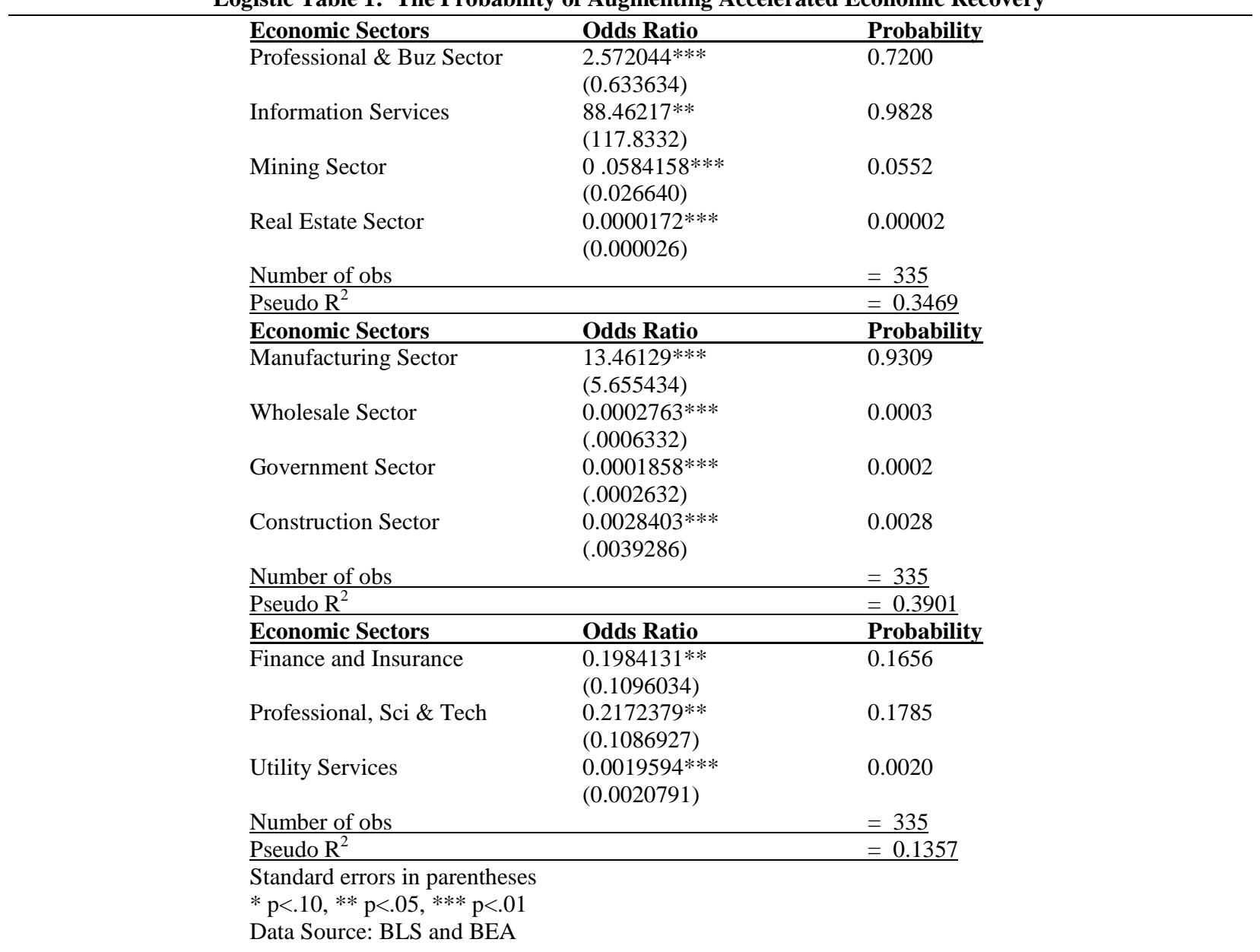

\section{ANALYSIS OF RESULTS}

Tabled results present odds ratios and probability of impacting economic recovery parameters associated with selected sectors and sub-sectors of the US economy. The results, to some degree lend credence to views of growing number of analysts who espouse the notion that the finance and insurance sector of the US economy continue to exhibit diminishing potential to accelerate economic recovery after a major shock. Results show that appreciable growth among selected sectors of the US economy after a major economic shock such as the recession of 2008; is significant in understanding the pace of US economic recovery. This study finds that the likelihood that a sector or sub-sector will influence acceleration in US economic recovery after a major shock differs significantly among the various sectors tested. For instance, table 1 show that all things being equal, a percentage growth among 
firms in the professional and business services sector ${ }^{1}$ increases the probability of experiencing acceleration in economic recovery by $72 \%$. This outcome suggests that firms found in the sector possess the potential necessary to enhance the pace of US economic recovery after a major economic slowdown or recession. It further shows that a percentage growth among firms in the sector is relatively enough to significantly impact the pace of US economic recovery. Transformed logistic results further indicate that percentage growth in the mining sector after a major economic shock also has the potential to enhance the pace of economic recovery by $5.52 \%$. This outcome suggests the mining sector is not only crucial to economic growth; but also essential in providing the impetus needed to accelerate economic recovery after economic slowdown. Firms found in this sector include the oil and gas extraction firms as well as precious and semi-precious stones mining corporations.

Appreciable growth in the information service sub-sector of the US economy (made up of firms in the publishing industries, motion pictures and sound industry, broadcasting and telecommunication and data processing industry) after a major shock is also significant in US economic recovery. A percentage growth among firms in the sub-sector increases the likelihood of experiencing acceleration in recovery by $98 \%$; the highest probability found in this study. This strong outcome is significant and highlights growing importance of the information services sector to the US economy. A review of the literature provides some clues about conditions which might explain this strong recovery potential. First, some conclusions suggests the outcome might be an indication that firms in the sub-sector tend to be less susceptible to shocks or are less impacted during a major economic downturn. This condition makes it easier to recovery faster to augment post-recession growth. Secondly, it is also suggested that firms in the sector might be characterized by relatively faster rebound potential which makes it possible for the sector to significantly impact recovery after a major economic shock. Whichever reason best explains the sector's performance, test results indicates firms in the industry possess strong potential to spearhead recovery after a major economic shock.

The probability of impacting economic recovery feature associated with the real estate sub- sector on the other hand, reflects the ongoing problem in the sub-sector. The sub-sector is one of the key segments of the economy considered by most Americans as a measure of progress in the economic recovery. This study however, finds that the sub-sector exhibits weak potential to enhance the pace of economic recovery after major economic shock. A percentage growth among firms in the sector increases the likelihood of experiencing acceleration in economic recovery by only $0.002 \%$. This outcome is also significant in that, the condition could explain why the real estate sub-sector of the economy is still struggling after the mortgage crisis of 2008. The real estate sub-sector still lags behind other sectors of the US economy even after various government incentives to revamp the sub-sector. Various programs such as the home buyer's credits by the federal government and relatively low house prices coupled with low mortgage loan rates, have all failed to bring the real estate market back to pre-2008 levels. This result however, does not necessarily mean the sector is insignificant in economic recovery or growth; it rather shows the sector exhibit a weak potential or might have been decimated during the recession to the extent that it currently lacks the capacity and the growth prospect critical to significantly impact ongoing recovery process.

Although the impact of the manufacturing sector on US economic growth in recent years have been waning due to massive outsourcing and expansion of the Chinese economy, test result indicates the sector is still crucial to US economic recovery. Table 1 show that a percentage growth among firms in the industry increases the probability of experiencing acceleration in economic recovery by 93\%; the second highest probability of impacting economic recovery prospect in this study. This outcome is significant and supports growing calls for increased investments in the manufacturing sector if the US economy can be restored to its pre-recession growth trajectory. The wholesale sub-sector, a key component in measuring consumer confidence in the rebound process, is also significant in US economic recovery. However, the sub-sector's impact on recovery is minimal than expected. A percentage growth among firms in the sub-sector only increases the likelihood of experiencing accelerated economic recovery by $0.03 \%$. Thus, a percentage growth among firms in the sub-sector does not generate enough boosts critical to ensure accelerated economic recovery after economic slowdown.

\footnotetext{
${ }^{1}$ The professional and business services sector consists of these sectors: Professional, Scientific, and Technical Services: NAICS 54, Management of Companies and Enterprises: NAICS 55 and Administrative and Support and Waste Management and Remediation Services: NAICS 56
} 
The government services sector, according to test results, is also less critical in economic recovery. A percentage growth among entities in the sector increases the likelihood of experiencing a boost in economic recovery by $0.02 \%$. Additionally, the construction sector also exhibit surprisingly low potential to substantially impact recovery after a major shock. A percentage growth among firms in this sector after a major shock increases the probability of observing acceleration in economic recovery by $0.28 \%$. This outcome might explain why Federal funded infrastructure development drive (shovel ready jobs) initiated in the wake of the economic crisis failed to have the expected impact on recovery. These findings however, do not suggest that sectors with weak potential to impact economic recovery have no role in economic growth. It is important to point out that this study only measures the probability to substantially impact economic recovery after a major economic slowdown and not the impact of sector performance on general economic growth. Sectors of the US economy as evidenced in growth data (Bureau of Economic Analysis Data), tend to absorb economic shock differently. As a result, they also tend to exhibit different rebound rates which consequently define the critical role they play in economic recovery. For sectors with lower than expected likelihood of significantly impacting economic recovery, it is possible that the condition stems from other integral factors aside what this study controlled for. It is also possible that for some sectors and sub-sectors of the economy, a relatively higher percentage growth among its firms is required to provide the boost needed to substantially impact economic recovery.

To some degree, the finance and insurance sector of the US economy, which is the focus of this study, reflects growing views among critics about the sector's ability to significantly impact and spearhead recovery of the US economy after a major shock. Critics argue that although the sector's contributions are still critical in economic growth, it continue to exhibit diminishing potential to substantially rally other sectors of the economy towards the long awaited full recovery after the 2008 collapse. Table 1 indicates growth among firms in the sector is significant in economic recovery as expected; however, a percentage growth among firms in the sector increases the likelihood of experiencing accelerated economic recovery by only 16.56\%. Compared to other sectors such as the manufacturing and professional and business services sectors, the finance and insurance sector, contrary to perceived importance, seems to exhibit waning resilience and capabilities to significantly impact the pace of US economic recovery. The probability to substantially impact economic recovery value $(16.56 \%)$ is significant; however, considering the relative importance often attached to growth among firms in the sector, this study expected a relatively higher potential to impact economic recovery. The professional, scientific and technical services subsector of the economy (made up of firms such as the legal services, computer systems design and related services etc) is similarly critical in US economic recovery. Results show that post-shock growth among firms in the subsector increases the likelihood of realizing significant boost in the pace of economic recovery by $17.85 \%$. This revelation that the professional, scientific and technical services sub-sector is more critical to US economic recovery than the finance and insurance sector, further supports growing sentiments among some analyst that the US financial and insurance sector has lost some of its comparative strength in influencing macroeconomic conditions in the domestic market.

Test result further show the Utility services sector, like other sectors tested in this study, also lack the potential to significantly impact and sustain meaningful economic recovery. Although the sector (according to the energy-economic growth nexus literature) is critical in economic growth, a percentage growth among firms in the sector is found to be inadequate to significantly promote accelerated economic recovery all things being equal.

This study has shown that sector and sub-sector contributions to US GDP growth are critical in sowing the seed for accelerated recovery after a major economic shock. The study has further shown that despites its role as a key sector in a meaningful economic growth, the finance and the insurance sector of the economy, contrary to what most Americans believe, do not exhibit the best potential in accelerating the pace of economy recovery after a major shock.

\section{CONCLUSION}

This study finds that appreciable growth among (selected key) sectors and sub-sectors of the US economy is important in understanding the pace economic recovery after a major shock. Test results show that individual sectors or sub-sectors of the economy exhibit varied rebound potentials in the economic recovery process. Although the finance and insurance sector is still critical in US economic recovery after a major economic shock, this study finds that the sector's potential to significantly impact the pace of economic recovery seem to be overstated 
compared to other key sectors of the economy. Test results show that sectors, such as manufacturing and professional and business service, exhibits relatively higher potential to promote acceleration in economic recovery than the finance and insurance sector (often regarded as the dominant sector with the potential to spearhead economic recovery). This study could only speculate the pace of the current recovery process if government intervention after the 2008 collapse were channeled toward bolstering the manufacturing and information services sectors of the economy; given that these sectors exhibits relatively higher potential to significantly impact the pace of economic recovery after a major shock. These findings could inform future economic policies geared towards accelerating growth and recovery after a major shock such as the recession of 2008. It could serve as the basis for targeting specific sectors of the economy if the goal is to accelerate the rate of economic recovery after a major shock.

\section{AUTHOR INFORMATION}

Rexford Abaidoo PhD; is Assistant Professor of Business Administration and Quantitative methods at the University of Maryland Eastern Shore. Teaching areas include corporate finance, business statistics, scientific methods in business and computer application in business. Research mainly focuses on dynamics of economic growth and recovery, international finance and competitiveness and consumer behavior. E-mail: rabaidoo@umes.edu

\section{REFERENCES}

1. $\quad$ Arestis, P., P. O. Demetriades and K. B. Luintel (2001), "Financial Development and Economic Growth: The Role of Stock Markets", Journal of Money, Credit, and Banking, 33: 16-41.

2. Beck, T. and R. Levine (2002), "Industry Growth and Capital Allocation: Does Having a Market- or BankBased System Matter?", Journal of Financial Economics, 64: 147-180.

3. Brown and Lundblad (2009), The US Economic Crisis: Root Causes and the Road to Recovery. Journal of Accountancy; October 2009.

4. Christopoulos, D. K. and E. G. Tsionas (2004), "Financial Development and Economic Growth: Evidence from Panel Unit Root and Cointegration Tests", Journal of Development Economics, 73: 55-74.

5. Ćurak M ,Lončar S and Poposki K (2009) Insurance Sector Development and Economic Growth in Transition Countries. International Research Journal of Finance and Economics - Issue 34 (2009).

6. De la Fuente, Angel and J.M. Marin. (1995). "Innovation, 'Bank' Monitoring and Endogenous Development." UFAE and IAE Working Papers 307.95, Unitat de Fonaments de l'Anàlisi Econòmica (UAB) and Institut d'Anàlisi Econòmica (CSIC).

7. Damien Josefiak American Insurance Association 1 October 9, 2006. http://www.aiadc.org/AIAdotNET/docHandler.aspx?DocID=298519.

8. Demirguc-Kunt, Asli and Ross Levine. (2001). Financial Structure and Economic Growth: A CrossCountry Comparison of Banks, Markets, and Development. Cambridge: The Massachusetts Institute of Technology Press.

9. Greenwood, J. and B. Jovanovic (1990), "Financial Development, Growth, and the Distribution of Income", Journal of Political Economy, 98: 1076-1107.

10. Hosmer, D. W., Jr., \& Lemeshow, S. (2000). Applied logistic regression (2nd ed.). New York: Wiley.

11. İlhan EGE et al (2011) The Relationship Between Insurance Sector And Economic Growth: An Econometric Analysis. Int. J. Eco. Res., 2011, 2(2), 1-9.

12. Levine, Ross(2004). Finance and Growth: Theory and Evidence Carlson School of Management, University of Minnesota and the NBER.

13. Levine, R. and S. Zervos (1998), "Stock Markets, Banks and Economic Growth", American Economic Review, 88, 3, pp.537-558.

14. Manning J. Mark (2003) Finance Causes Growth: Can We Be So Sure? Contributions to Macroeconomics, Vol 3 issue 1.

15. Marco Arena (2006) Does Insurance Market Activity Promote Economic Growth? A Cross- Country Study for Industrialized and Developing Countries. World Bank Policy Research Working Paper 4098, December 2006. 
16. Menard, S. (2000). Coefficients of determination for multiple logistic regression analysis. The American Statistician, 54(1), 17-24.

17. Peng, C. Y., Manz, B. D., \& Keck, J. (2001). Modeling categorical variables by logistic regression. American Journal of Health Behavior, 25(3), 278-284.

18. Peng, C. Y., \& So, T. S. H. (2002a). Modeling strategies in logistic regression. Journal of Modern Applied Statistical Methods, 14, 147-156.

19. Rajan, R. and L. Zingales (1998a), "Financial Dependence and Growth", American Economic Review, 88, pp.559-586.

20. Rousseau, P. L. and P. Wachtel (1998), "Financial Intermediation and Economic Performance: Historical Evidence from Five Industrial Countries", Journal of Money, Credit and Banking, 30: 657-678.

21. Rousseau P and Wachtel P (2005) Economic Growth and Financial Depth: Is the Relationship Extinct Already? UNU / WIDER conference on Financial Sector Development for Growth and Poverty Reduction July 1-2, 2005 Helsinki.

22. US Bureau of Economic Analysis Data Sets.

23. US Census Bureau Data Sets.

24. Zhiwei Zhang and Wenlang Zhang (2010), The Road to Recovery: Fiscal Stimulus, Financial Sector Rehabilitation, and Potential Risks Ahead. 